\title{
ANDERSEN-TAWIL SYNDROME WITH HIGH RISK OF SUDDEN CARDIAC DEATH IN FOUR MEXICAN PATIENTS. CARDIAC AND EXTRA-CARDIAC PHENOTYPES
}

\author{
David R. Barrón-Díaz ${ }^{1,2}$, Armando Totomoch-Serra ${ }^{3,4}$,, Rosa E. Escobar-Cedillo ${ }^{5}$, \\ Alan García-Gutierrez ${ }^{1}$, Álvaro E. Reyes-Quintero ${ }^{1}$, Sergio E. Villegas Davirán ${ }^{5}$, \\ CONCEPCIÓn B. IBARRA-Miramón ${ }^{6}$, AND MANLIO F. MÁrQUEZ ${ }^{1 *}$
}

${ }^{1}$ Department of Electrophysiology, Instituto Nacional de Cardiología "Ignacio Chávez", Mexico City; ${ }^{2}$ Social Service Program, Faculty of Medicine, Universidad Autónoma de Coahuila, Unidad Torreón, Coah.; ${ }^{3}$ Department of Genetics and Molecular Biology, Centro de Investigación y Estudios Avanzados del Instituto Politécnico Nacional, Mexico City; ${ }^{4}$ Doctoral Program in Medical Science, Universidad de la Frontera, Temuco, Chile; ${ }^{5}$ Electrodiagnosis and Muscular Dystrophy Service, Instituto Nacional de Rehabilitación "Luis Guillermo Ibarra Ibarra”, Mexico City; ${ }^{6}$ Department of Evaluation and Treatment, Centro Nacional Modelo de Atención, Investigación y Capacitación para la Rehabilitación e Integración Educativa "Gaby Brimmer," Mexico City, Mexico

IT These authors contributed equally.

\begin{abstract}
Background: Andersen-Tawil syndrome (ATS) is a cardiac channelopathy that is inherited in an autosomal dominant way, and it is characterized by a triad of periodic paralysis, ventricular arrhythmias, and includes some dysmorphic features with incomplete penetrance and variable expression that result in a challenging diagnosis. Objective: The objective of the study was to describe the cardiac and extra-cardiac phenotype in a cohort of patients with ATS at risk of sudden cardiac death (SCD) to improve its early clinical identification. Methods: In an observational, transversal study, with a deviant case sampling, four female patients with ATS at high risk of SCD were included in the study. They carried the heterozygous pathogenic variants C.407C $>$ T [p.Ser136Phe], c.652C>T [p.Arg218Trp] ( $n=2)$, and c.431G>C [p.Gly144Ala] in the KCNJ2 gene. Patients were evaluated by a cardiologist, a clinical geneticist, and a physiatrist. Results: One patient had the classical facial phenotype and the other three had subtle manifestations. The group of patients presented a diverse set of clinical data such as: triangular face, broad forehead, broadening of medial eyebrows, auricular pits, low-set ears, eyelid ptosis, thin lips, mandibular hypoplasia, and diverse types of dental alterations, single transverse palmar crease, camptodactyly, and syndactyly. Long-exercise test showed a decrement in the percentage amplitude up to $44 \%$, classifying patients in IV or V types according to Fournier's scale. Conclusions: Extracardiac manifestations were a common finding in this series of ATS type1 at high risk of SCD. Its recognition could help the clinician in the early identification of patients with ATS, especially for the cardiologist since they are commonly referred only for evaluation of ventricular arrhythmias. (REV INVEST CLIN. 2021;73(3):XX-XX)
\end{abstract}

Key words: Andersen-Tawil syndrome. Phenotypic variability. KCNJ2 pathogenic variants. Long-exercise electrophysiological test. Periodic paralysis.

*Corresponding author:

Manlio F. Márquez

E-mail: manlio.marquez@gmail.com
Received for publication: 25-06-2020

Approved for publication: 02-09-2020

DOI: $10.24875 /$ RIC.20000310

0034-8376 / (c) 2020 Revista de Investigación Clínica. Published by Permanyer. This is an open access article under the CC BY-NC-ND license (http://creativecommons.org/licenses/by-nc-nd/4.0/). 


\section{INTRODUCTION}

In approximately $60 \%$ of the cases of Andersen-Tawil syndrome (ATS) (MIM\# 170390), heterozygous pathogenic variants in the gene KCNJ2 (locus 17q23.1-q24.2) affect the alpha subunit of the inward rectifier potassium channel 2 (Kir2.1), causing alterations in the resting action potential in skeletal muscle and the depolarization phase in cardiac muscle. This cardiac channelopathy affecting the $\mathrm{KCNJ} 2$ is inherited in an autosomal dominant way, and in one clinical case by biophysical analysis is inferred $\mathrm{KNCJ} 5$ as a cause of ATS.

The KCNJ2 covers more than 330 variants informed in the different database (www.ncbi.nlm.nih.gov/clinvar) and near to 94 variants are classified as pathogenic or likely pathogenic as a cause of Short QT syndrome 3, familial atrial fibrillation or ATS (www.hgmd. (f.ac.uk), and the participation of additional variants in nuclear and mitochondrial genome is under analysis.

This disease is characterized by a clinical triad of subtle dysmorphisms (mainly facial), ventricular arrhythmias, and periodic paralysis (PP $)^{1,2}$. An important burden in cardiac alterations includes premature ventricular contractions (PVC), prominent $U$ waves, wide $\mathrm{T}-\mathrm{U}$ junction, prolonged $\mathrm{Q}-\mathrm{U}$ interval, and ventricular tachyarrhythmias. It also includes polymorphic or bidirectional ventricular tachycardia, syncope, and in some cases, a family history of sudden cardiac death $(\mathrm{SCD})^{3,4}$.

In tertiary health centers, a significant part of the clinical cases is identified through the analysis of a classical cardiac rhythm disorder plus a high suspicious index by the cardiologists.

However, when the cardiac phenotype is not predominant, the cases can be derivate to neurology or rehabilitation services for the analysis of muscular weakness or PP, and in few cases, these are referred to the medical geneticist by general practitioners or specialists with interest in clinical genetics, where mandibular hypoplasia is the main symptom of suspicion, to rule out the Perre-Robin ${ }^{2}$ sequence or as a differential diagnosis of 22 q 11 del ${ }^{5}$ syndrome. In this context, the participation of the medical geneticist is scarce in the analysis of the phenotype in the several ATS cases reported and the development of the "facial gestalt" is hard to develop ${ }^{6}$ for these diseases because the low frequency in Mexico and worldwide.

Patients with ATS had a clinical variable expression and incomplete penetrance $(\sim 80 \%)^{7}$ hindering the diagnosis to the varied group of specialists attending these patients. These specialists belong to areas such as internal medicine, rehabilitation, medical genetics, cardiology, neurology, physical medicine, and rehabilitation. From a cardiologist perspective, the disease is related to heart rhythm disorders, specifically ventricular arrhythmias, in the presence of a long Q-U interval. The extra-cardiac phenotype produces facial dysmorphism. The significant features are low-set ears, a broad forehead, short palpebral fissures, hypertelorism, full nasal bridge with a bulbous tip, and maxillary and mandibular hypoplasia ${ }^{8}$. In addition, the skeletal phenotypic alterations may also present dysmorphic features as clinodactyly, syndactyly, short stature, and scoliosis.

As PP is one of the main features of the disease, the screening of suspected cases has been proposed through post-exercise electrophysiological tests. These can be helpful to distinguish among different muscle disorders because different patterns of the compound muscle action potentials (CMAP) changes over time and correlate with specific pathogenic variants ${ }^{9-11}$. Throughout a long-exercise test protocol, it is possible to differentiate patients with dystonic myopathy (a pattern I, II, or III in the Fournier scale) and PP (pattern IV and V) ${ }^{7}$. Specifically, in pattern IV, it is observed an initial increase in the CMAP amplitude posterior to the exercise and a posterior late decrease. Concerning the pattern V, it is noticing a late decrease in the CMAP amplitude? .

The objective of this work was to describe the cardiac and extra-cardiac phenotype in a cohort of patients with ATS and the high risk for SCD, to increase the probability of finding patients without a classic phenotype, who are treated in neuromuscular and rehabilitation clinics. In addition, it is intended to increase the phenotypic heritage for a future genotypephenotype correlation in a wider sample.

\section{METHODS}

Four female patients attending a cardiological center in Mexico City, with a confirmed diagnosis of ATS by 
Table 1. Clinical data identified in four Mexican female patients with ATS

\begin{tabular}{|c|c|c|c|c|}
\hline Clinical data & Case $1^{*}$ & Case 2* & Case 3 & Case 4 \\
\hline Pathogenic variant & \multicolumn{2}{|c|}{ c.652C>T [p.Arg218Trp]* } & $\begin{array}{l}\text { c. } 407 \mathrm{C}>\mathrm{T} \\
{[\mathrm{p} . \operatorname{Ser} 136 \mathrm{Phe}]}\end{array}$ & $\begin{array}{l}\text { c. } 431 \mathrm{G}>\mathrm{C} \\
\text { [p.Gly144Ala] }\end{array}$ \\
\hline Sudden death history & Mother & Mother & NFCA & No \\
\hline Limbs weakness history & Yes & Yes & Yes & Yes \\
\hline Cardiac affectation & No & $\begin{array}{l}\text { Arrhythmia plus Severe } \\
\text { mitral regurgitation }\end{array}$ & No & No \\
\hline Syncope & Yes & Yes & Yes & Yes \\
\hline Visuospatial alterations & No & No & No & Yes \\
\hline
\end{tabular}

*Both cases belong to the same family. NFCA: non-fatal cardiac arrest.

genetic test (ATS type 1 ) and high risk of SCD (defined as the history of SCD in a family member or an episode of non-fatal cardiac arrest) were included in an observational, transversal study, with a deviant case sampling (Table 1). They were evaluated in two medical centers that provide tertiary level services in Mexico. The first center was the National Institute of Cardiology and the other the National Institute of Rehabilitation.

A genetic testing confirmed four different heterozygous $K C N J 2$ missense pathogenic variants, including c.652C > T [p.Arg218Trp] ${ }^{12}$ (two patients), c.407C > T [p.Ser136Phe ${ }^{13}$, and c.431G>C [p.Gly144Ala ${ }^{13}$ (Supplementary Table 1), altering highly conserved sites in the protein (Supplementary Tables 1 and 2). From the patients considered at high risk of SCD, three of them already had an implantable cardioverter-defibrillator (ICD) for secondary prevention. They have been monitored for at least four years by a medical geneticist and a cardiologist specialized in cardiac channelopathies through a standard resting 12-lead electrocardiogram (ECG). Furthermore, the patients had a $24 \mathrm{~h}$ Holter monitoring at each 6-months visit at the Channelopathies Clinic of the National Institute of Cardiology.

A physiatrist in the Department of Muscular Dystrophy and Electrography at the Instituto Nacional de Rehabilitación Luis Guillermo Ibarra Ibarra analyzed the electrophysiological characteristics of skeletal muscle. Through various neurophysiological tests, the motor and sensory neuroconduction were analyzed through the study of the median, ulnar, peroneal, and sural nerves using surface electrodes and conventional techniques to analyze muscle weakness. To further study the muscle characteristics, electromyography (EMG) needle was inserted in proximal and distal limb segments to test muscular activity at rest and during exercise. Finally, it was carried out a set of special studies such as short and long-exercise tests according to Fournier's method ${ }^{9}$ in an attempt to analyze a possible correlation and identification of cases with ATS and their pathogenic variants found in the genetic test.

All the procedures were made according to the declaration of Helsinki, and the patients signed informed consent. The protocol was approved by the Institutional Research and Bioethics Committees of the Instituto Nacional de Cardiología Ignacio Chávez (Project number 17-1003).

\section{RESULTS}

\section{Arrhythmic phenotype}

After explaining the benefits, risks, and limitations of the placement of an ICD, one of the patients decided that the device should not be placed. Therefore, three patients underwent an ICD implantation. In all subjects, the cardiac symptoms started before 25 years (Table 2). Cases 1 and 2 belonged to the same family. They had a family history of SCD in one sister and the mother. Table 3 shows the main ECG parameters. The mean QTc interval was 460 ms considering that only two patients had prolonged a QTc interval (441 and $544 \mathrm{~ms}$ ). All patients showed prominent $U$ waves with "U on P" sign and showed a prolonged Q-Uc interval up to $725 \mathrm{~ms}$ with a mean of $663 \mathrm{~ms}$. 
Table 2. Cardiac manifestations in patients with Andersen-Tawil syndrome

\begin{tabular}{lcccl}
\hline Case number & $\begin{array}{c}\text { Cardiac symptom } \\
\text { age onset }\end{array}$ & ICD & $\begin{array}{c}\text { Primary or secondary } \\
\text { prevention ICD }\end{array}$ & Risk factor for ICD implantation \\
\hline 1 & 25 years & - & - & *Syncope, s-VT \\
2 & $\sim 7$ years & + & 1 & Syncope, s-VT \\
3 & 15 years & + & 2 & Syncope, s-VT and NFCA \\
4 & 11 years & + & 1 & Syncope \\
\hline
\end{tabular}

ICD: implantable cardioverter-defibrillator. 1: primary prevention ICD; 2: secondary prevention ICD.

*Waiting for ICD placement (Due her risk factors). NFCA: non-fatal cardiac arrest; s-VT: sustained ventricular tachycardia.

Table 3. ECG characteristics of patients with ATS

\begin{tabular}{|c|c|c|c|c|c|c|c|c|c|c|c|c|c|c|}
\hline $\begin{array}{l}\text { Case } \\
\text { number }\end{array}$ & $\begin{array}{c}\mathrm{HR} \\
(\mathrm{Bpm})\end{array}$ & $\begin{array}{c}\text { PR } \\
(\mathrm{ms})\end{array}$ & $\begin{array}{c}\mathrm{QT} \\
(\mathrm{ms})\end{array}$ & $\begin{array}{l}\text { QTC } \\
\text { (ms) }\end{array}$ & $\begin{array}{c}\mathrm{T} \\
(\mathrm{ms})\end{array}$ & $\begin{array}{c}\mathrm{T}-\mathrm{U} \\
\text { junction }\end{array}$ & $\begin{array}{l}\mathrm{Q}-\mathrm{U} \\
(\mathrm{ms})\end{array}$ & $\begin{array}{c}\text { Q-U C } \\
(\mathrm{ms})\end{array}$ & $\begin{array}{c}\text { U wave } \\
\text { height } \\
\text { V2-V3 } \\
(\mathrm{mv})\end{array}$ & $\begin{array}{l}\text { U wave } \\
\text { width } \\
\text { V2 (ms) }\end{array}$ & $\begin{array}{l}\text { U wave } \\
\text { width } \\
\text { V3 (ms) }\end{array}$ & $\begin{array}{l}U \text { in } \\
V 5\end{array}$ & $\begin{array}{c}\text { U wave } \\
\text { on inferior } \\
\text { leads (ms) }\end{array}$ & $\begin{array}{l}U \text { on } \\
P \text { sign }\end{array}$ \\
\hline 1 & 73 & 134 & 400 & 441 & 280 & + & 600 & 661 & $0.2 \mathrm{mV}$ & 200 & 200 & + & NV & + \\
\hline 2 & 87 & 120 & 480 & 544 & 280 & - & 640 & 725 & $0.2 \mathrm{mV}$ & 200 & 200 & + & 160 & + \\
\hline 3 & 58 & 160 & 440 & 433 & 200 & + & 600 & 590 & $0.3 \mathrm{mV}$ & 160 & 120 & - & NV & + \\
\hline 4 & 67 & 160 & 400 & 423 & 280 & + & 640 & 676 & $0.2 \mathrm{mV}$ & 200 & 160 & - & NV & + \\
\hline
\end{tabular}

HR: heart rate; PR: PR interval; QT: QT interval; QTc: QT interval corrected by Bazett formula; Q-U: Q-U interval; Q-Uc: Q-U interval corrected by Bazett formula. ECG: electrocardiogram.

Table 4. Holter characteristics in patients with ATS

\begin{tabular}{|c|c|c|c|c|c|c|c|}
\hline $\begin{array}{l}\text { Case } \\
\text { number }\end{array}$ & VT type & BVT & PVC & $\begin{array}{l}\text { Ventricular } \\
\text { bigeminy }\end{array}$ & Couplets & Triplets & $\begin{array}{l}\text { Percentage } \\
\text { of PVC* }(\%)\end{array}$ \\
\hline 1 & NSVT & No & + & + & + & + & 5.06 \\
\hline 2 & PVT & No & + & + & + & + & 34.40 \\
\hline 3 & NSPVT & + & + & + & + & + & 29.61 \\
\hline 4 & NSVT & + & + & + & + & + & 8.25 \\
\hline
\end{tabular}

BVT: bidirectional ventricular tachycardia; NSVT: non-sustained ventricular tachycardia; NSVPT: non-sustained polymorphic ventricular tachycardia; PVC: premature ventricular contractions; PVT: polymorphic ventricular tachycardia.

*This percentage corresponds to one Holter monitoring.

The results of 24-h Holter monitoring are described in Table 4. We documented in all patients PVC, with a $24-\mathrm{h}$ burden, from $5 \%$ to $34 \%$. The presentation included ventricular bigeminy, couplets, triplets, and episodes of ventricular tachycardia (VT): $50 \%$ with monomorphic VT and $50 \%$ had polymorphic VT. One subject had sustained VT with polymorphic VT. Bidirectional VT was present in one patient.

\section{Extra-cardiac phenotype}

Table 5 shows the extra-cardiac phenotypic characteristics of the four cases. The most common facial features in the four patients were mandibular hypoplasia in all the cases ( $100 \%)$, plus triangular face, broadening of forehead, broadening of medial eyebrows, and eyelid ptosis in three cases (75\%). Concerning the limbs, the most common finding was camptodactyly in hands (75\%) and $2^{\text {nd }}-3^{\text {rd }}$ feet syndactyly (100\%). All the patients had clinical history of a diverse set of dental alterations, though not assessable by physical examination in two patients because they had previous orthodontic treatment (Supplementary Fig. 1).

\section{Electrophysiological testing}

Table 6 shows the main results of the electrophysiological studies performed to identify alterations in 
Table 5. Phenotypic manifestations in patients with Andersen-Tawil syndrome

\begin{tabular}{|c|c|c|c|c|}
\hline Clinical characteristics & Case 1 & Case 2 & Case 3 & Case 4 \\
\hline Low height & Yes & Yes & No & No \\
\hline Triangular face & No & Yes & Yes & Yes \\
\hline Broad forehead & Yes & Yes & Yes & No \\
\hline Broadening of medial eyebrow & Yes & Yes & Yes & No \\
\hline Ptosis palpebral & Yes & Yes & Yes & Yes \\
\hline Down-slanting palpebral fissures & Yes & Yes & No & No \\
\hline Myopia & No & No & Yes & Yes \\
\hline Flat nasal bridge & No & Yes & No & No \\
\hline Bulbous nose & No & Yes & No & Yes \\
\hline Malar hypoplasia & Yes & Yes & No & No \\
\hline Mandibular hypoplasia & Yes & Yes & Yes & Yes \\
\hline Dental alterations & Yes & Yes & Yes & Yes \\
\hline Thin lips & No & No & Yes & Yes \\
\hline Low-set ears & No & Yes & Yes & No \\
\hline Auricular pits & No & No & Yes & Yes \\
\hline Unilateral hypoacusia & No & No & No & Yes \\
\hline Scoliosis & No & Yes & No & No \\
\hline Camptodactyly in hands & Yes & Yes & No & Yes \\
\hline Clinodactyly & Yes & Yes & Yes & No \\
\hline Single transverse palmar crease & No & No & Yes & No \\
\hline Feet syndactyly & Yes & Yes & Yes & Yes \\
\hline
\end{tabular}

skeletal muscle due to the potassium channel dysfunction. In most cases, we found motor neuroconduction in normal ranges, but the patient number three had a decrement in the motor neuroconduction amplitude potential in median, ulnar, and peroneal nerves. Sensitive neuroconduction studies had normal parameters in all patients.

Needle EMG testing showed that $50 \%$ of membrane instability values mimic the typical pattern of myopathy in patients 2 and 3; the other patients had normal patterns. We did not find abnormalities short-exercise test, and the majority of the patients showed a minimum decrement in the amplitude voltage. The electrophysiological studies found a relevant result in the long-exercise test: a significant decrement in the amplitude percentage in the range of $44-64.5 \%$, classifying patients in IV or V types according to the Fournier's scale (Fig. 1). The decrement in the amplitude and area at the CMAP was up to $60 \%$ in all patients (Table 6 ).

\section{DISCUSSION}

ATS is a disease with unknown frequency, due to the limited information contained in the literature that could be described as an ultra-rare disease (1:500,000$2,000,000)^{14}$. However, this number can be overrepresentative. A significant part of patients with ATS does not present the typical triad, which makes difficult the identification of the phenotype where there is not a significant cardiac affectation.

The external phenotype identified in this group of Mexican patients with ATS agree with the clinical data previously informed in literature ${ }^{15,16}$, where the more common features were a triangular head, broad forehead, flared eyebrow, ptosis palpebral, mandibular hypoplasia, dental alterations, thin lips, camptodactyly, clinodactyly in feet, syndactyly, and muscle weakness. However, the case 2 had a typical appearance with the bulbous nose present and diverse 
Table 6. Electrophysiology characteristics of the skeletal muscle in patients with Andersen-Tawil syndrome

\begin{tabular}{|c|c|c|c|c|c|c|c|c|}
\hline $\begin{array}{l}\text { Case } \\
\text { number }\end{array}$ & Symptoms & $\begin{array}{l}\text { Motor } \\
\text { neuro- } \\
\text { conduction }\end{array}$ & $\begin{array}{l}\text { Sensitive } \\
\text { neuro- } \\
\text { conduction }\end{array}$ & $\begin{array}{l}\text { Needle E } \\
\text { MG }\end{array}$ & $\begin{array}{l}\text { Amplitude } \\
\text { changes } \\
\text { at CMAP in } \\
\text { the SET (mv) }\end{array}$ & $\begin{array}{l}\text { Amplitude } \\
\text { decrement } \\
\text { at CMAP } \\
\text { in the LET }\end{array}$ & $\begin{array}{l}\text { Area } \\
\text { decrement } \\
\text { at CMAP } \\
\text { in the LET }\end{array}$ & $\begin{array}{l}\text { Fournier } \\
\text { scale in } \\
\text { the LET }\end{array}$ \\
\hline 1 & Asymptomatic & Normal & Normal & Normal & $\begin{array}{l}\text { Increment } \\
\text { from } 7.6 \% \\
\text { to } 18.7 \% \\
\text { and then } \\
\text { decrement } \\
\text { to basal level }\end{array}$ & $\begin{array}{l}50 \% \text { (basal) } \\
64.2 \% \\
\text { (maximum } \\
\text { amplitude) }\end{array}$ & $\begin{array}{l}60.2 \% \\
\text { (basal) } \\
71.2 \% \\
\text { (maximum } \\
\text { valor) }\end{array}$ & Type IV \\
\hline \multirow[t]{2}{*}{2} & $\begin{array}{l}\text { Weakness } \\
\text { crisis }\end{array}$ & Normal & Normal & $\begin{array}{l}\text { Repose: } \\
\text { Membrane } \\
\text { instability } \\
\text { EMG patron } \\
\text { look like } \\
\text { myopathic }\end{array}$ & $\begin{array}{l}\text { Decrement } \\
\text { from } 16.2 \% \\
\text { to } 24.7 \%\end{array}$ & & & \\
\hline & & & & & $\begin{array}{l}\text { Decrement } \\
\text { from } 5.5 \% \\
\text { to } 10.5 \text { after } \\
\text { cooling }\end{array}$ & $\begin{array}{l}57.3 \% \\
\text { (basal) }\end{array}$ & $\begin{array}{l}77 \% \\
\text { (basal) }\end{array}$ & Type V \\
\hline 3 & $\begin{array}{l}\text { Weakness } \\
\text { crisis }\end{array}$ & $\begin{array}{l}\text { CMAP } \\
\text { decreased } \\
\text { in medianus, } \\
\text { ulnar and } \\
\text { peroneal } \\
\text { nerves }\end{array}$ & Normal & $\begin{array}{l}\text { Repose: } \\
\text { Membrane } \\
\text { instability } \\
\text { EMG patron } \\
\text { look like } \\
\text { myopathic }\end{array}$ & $\begin{array}{l}\text { Increment } \\
\text { from } 6.8 \\
\text { to } 10 \% \\
\text { then } \\
\text { decrement } \\
\text { to basal }\end{array}$ & $\begin{array}{l}44 \% \\
\text { (basal) }\end{array}$ & $\begin{array}{l}74.5 \% \\
\text { (basal) }\end{array}$ & Type V \\
\hline \multirow[t]{2}{*}{4} & $\begin{array}{l}\text { Little } \\
\quad \text { weakness }\end{array}$ & Normal & Normal & Normal & $\begin{array}{l}\text { Increment } \\
\text { from } 24.6 \% \\
\text { to } 39 \% \text {, } \\
\text { then showed } \\
\text { minimums } \\
\text { decrement }\end{array}$ & $\begin{array}{l}51.7 \% \\
\text { (basal) }\end{array}$ & $\begin{array}{l}45.2 \% \\
\text { (basal) }\end{array}$ & Type IV \\
\hline & & & & & & $\begin{array}{l}\text { 64.5\% } \\
\text { (maximum } \\
\text { amplitude) }\end{array}$ & $\begin{array}{l}62,7 \% \\
\text { (maximum } \\
\text { valor) }\end{array}$ & \\
\hline
\end{tabular}

CMAP: compound muscle action potential; EMG: electromyography; LET: long-exercise test; SET: short exercise test.

dental anomalies, which in conjunction with the cardiac alterations previously informed, helped to identify in 2015 the second pathogenic variant for Mexicans $^{12}$, and a variant of unknown significance in the CACN1C (under functional genomic study) since the first cases by Canun et al., ${ }^{2}$ and Plaster et al., ${ }^{17}$ carrying the pathogenic variant c.212A>T [p.Asp71Val]. However, the cases 1,3 , and 4 had attenuated facial alterations and were identified because in a detailed exploration, subtle alterations were showed and, in conjunction with a history of weakness, makes mandatory to perform KCNJ2 Sanger sequencing. A personal observation was the presence of broadening of the medial eyebrow in three of four cases; the frequency of this data must be verified in patients with
ATS and risk of SCD. With the development of new technologies such as 3D facial shape modeling, facial discrimination, including subtle features, a better diagnosis $^{18,19}$ of subtle facial phenotypes can be made in individuals with ATS.

A relevant observation of this work is the dental alterations were a constant in the group studied; abnormalities identified included dental crowding, enamel hypoplasia, hypodontia, hyperdontia, microdontia, and macrodontia ${ }^{7}$. The dental anomalies are considered underreported in ATS and the study of alterations in the development and growth of teeth could help to identify in a better way the participation of potassium channels in ATS. 
Figure 1. CMAP amplitude changes during long-exercise test protocol in four ATS cases with risk of SCD.

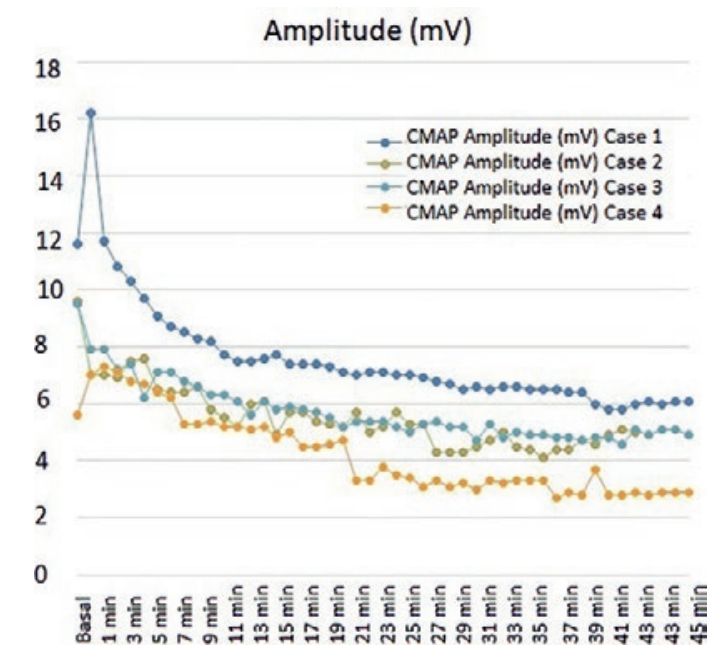

Due to the leading group of patients described in the literature are young people, we identify additional alterations developed as part of the natural history of the disease, for example, subtle psychological changes in the behavior in two patients were detected. In this context, the participation of Kir2.1 in the neuronal potential of action and the effect in the neurophenotype is under scrutiny.

The information published related to electrophysiological studies analyzing the skeletal muscle response either because of screening identification for genetic testing or weakness as the main clinical sign is scarce. In this respect, Fournier et al. described that performing a long-exercise test protocol can be able to detect a decrement in up to $40 \%$ in the CMAP7.

The results obtained, which present an early decrease in the CMAP (nadir 34-40 min in all patients), agree with a recent report by Song et al., that an initial decrement in the CMAP amplitude during prolonged exercise test in ATS cases $^{3}$; however, it is contrasted with the results obtained by Bendahhou et al. reported a delay in the CMAP amplitude after the prolonged exercise test ${ }^{20}$.

On the other hand, Tan et al. informed a higher sensibility for the identification of ATS cases with decreasing in the CMAP area compared with a decrease in the amplitude ${ }^{21}$. Three of the cases reported in this study agree with the results obtained by Tan et al. Furthermore, it was found myopathy potential patterns in two
ATS cases agrees with the report made by de Campos and de Carvalho, where it is included only one case 22 . In the present study, it was found a higher decrease in the CMAP compared to previous studies with a focus on the long test protocol ${ }^{20}$. However, PP was present only in one patient, and predominated the weakness in the diverse age stages, even in two patients associated with the menstruation cycle.

Twelve patients carrying the c.652C > T [p.Arg218Trp] pathogenic variant evaluated with the long test protocol in a recent Chinese cohort were studied. Authors were able to identify a substantial CMAP increase followed by a gradual reduction in amplitude ${ }^{9}$ which is concordant with the clinical history in our Case 1 (a case with two SCD in the family) ${ }^{12}$, but with a different morphology compared to Case 2 which has more alterations and also belongs to the same family. This pathogenic variant was included in a cohort of 11 patients with ATS, where $100 \%$ had modification $>40 \%$ in CMAP $^{21}$. In addition, Tan et al. (2012) proposed muscle velocity recovery cycles combined with repetitive stimulation as an alternative to long test protocol were also patients with p.Arg218Trp where easily identified ${ }^{23}$.

The c.431G>C [p.Gly144Ala] pathogenic variant supports the finding obtained in one patient by Ballester et al., ${ }^{24}$. This case was a Hispanic patient positive in clinical history for muscle weakness, but the findings are opposed to the clinical data found by Rai et al., ${ }^{25}$ where did not find muscle affectation when the LET 
was performed in seven Indian patients from two related families. In the present study, the patient carrier of the same variant had little weakness evaluated by LET, and she coincided with the patient informed by Ballester et al. Until now, there is no published information of positive LET patients carrying this pathogenic variant to compare the results obtained. Further studies, including ethnic differences and hormonal changes, will improve the results obtained in this part of the phenotype. On the other hand, to our knowledge, there are no data for LET studies, including the variant c.407C>T [p.Ser136Phe] and this study includes the first patient with specific electrophysiological studies in the skeletal muscle, including this pathogenic variant.

In ATS, the phenotype is remarkably heterogeneous, and the diagnosis has been firmly successful in some cases due to arrhythmic manifestations, combined with clinical experience in rare disease and availability of genetic testing to identify heterozygotes pathogenic variants in $\mathrm{KCNJ} 2$ and some cases, pathogenic variants in $K C N J 5(<1 \%)$. However, considering the frequency of this rare disease, there must be $>100$ patients in the country. This makes it mandatory to review the clinical, demographic, and physiological factors that could help to improve the identification of ATS cases in Mexico, taking into account that a great part of the patients reaches adulthood.

Furthermore, in a review of the literature performed by our research group until December 2018 in PubMed (pubmed.ncbi.nlm.nih.gov/), it was found 28 patients carrying the pathogenic variant c.652 C>T [p.Arg218Arg] (14 female- 14 male), this pathogenic variant causes a change of the arginine-basic amino acid into a tryptophan-nonpolar residue or an uncharged polar residue $(p . \operatorname{Arg} 218 \mathrm{Gln})^{17}$, this site is located within the $\mathrm{C}$-terminus domain of the alpha subunit of the strong inwardly-rectifying channel protein Kir2.1, causing a dominant-negative effect and diminished current of potassium, and also a decreased affinity for PIP2 has been reported for this domain ${ }^{26,27}$. The group of patients informed in literature had a range of 5-73 years old. This variant is considered as a hotspot according to literature $\mathrm{e}^{1,7,8,12,16,17,28-33}$, male cases have less affectation in cardiac and skeletal muscle, and facial and skeletal studies are under-reported, the clinical variable expression is a constant, and sudden death in $11 \%$ of the patients informed in the literature $7,16,34$.
The pathogenic variants c.407C>T [p.Ser136Phe], and c.431G>C [p.Gly144Ala], are less informed in literature, both variants are located in the $\mathrm{M} 1$ pore region, causing alterations in the selectivity of the pore channel leading to nonfunctional Kir2.1 channel ${ }^{4,17}$. In a study performed by Zhang et al., analyzing a subset of patients with pathogenic variants in the M1 pore region (including the two variants of these two patients) was found to a less dysmorphic phenotype, similarly in two patients included in the report. However, cardiac alterations were found in many of the patients included in the study. In this study, the muscle was evaluated through the research of PP finding in a low proportion of this clinical data, but specific information concerning the facial phenotype is scarce ${ }^{4}$.

Concerning the differences between cases with the same pathogenic variant, epigenetic, hormonal, and additional genetic factors are under scrutiny. The main factor currently under analysis by the research group is the participation of some haplotypes of the mitochondrial genome on the function, biogenesis, and protein interaction in the cardiac phenotype of ATS. As a first result, a greater presence of variants in the mitochondrial DNA of patients with ATS has been identified, which could have an influence on the manifestation of the disease ${ }^{13}$.

A limitation of this work is the size of the sample, as only four subjects affecting from this rare disease, with a particular phenotype and risk of SCD were included and analyzed.

The benefits of the early identification of patients with ATS is determining an adequate treatment, management, stratification of the risk of SCD and avoiding the use of amiodarone to prevent fatal outcomes $^{35,36}$, the monitoring of potassium levels avoids related hypokalemic alterations with weakness, and in some rare cases refer for plastic surgery intervention, to improve the quality of life of the patient. More studies are needed with a focus on the participation of genetics factors that lead to SCD and their interaction with environmental variables.

\section{ACKNOWLEDGEMENTS}

The authors would like to thank the study participants, health workers, and laboratory technicians at 
both Instituto Nacional de Rehabilitación "Luis Guillermo Ibarra Ibarra" and Instituto Nacional de Cardiología "Ignacio Chávez". Special thanks in particular for Dra. Guillermina Garcia from the Instituto Nacional de Rehabilitación who helps us coordinate all the studies. ATS would like to thank CONACYT and UFRO.

\section{SUPPLEMENTARY DATA}

Supplementary data are available at Revista de Investigación Clínica online (www.clinicalandtranslationalinvestigation.com). These data are provided by the corresponding author and published online for the benefit of the reader. The contents of supplementary data are the sole responsibility of the authors.

\section{REFERENCES}

1. Tristani-Firouzi M, Jensen JL, Donaldson MR, Sansone, Meola G, Hahn A, et al. Functional and clinical characterization of KCNJ2 mutations associated with LQT7 (Andersen syndrome). J Clin Invest. 2002;110:381-8

2. Canun S, Pérez N, Beirana LG. Andersen syndrome autosomal dominant in three generations. Am J Med Genet. 1999:85:147-56.

3. Song J, Luo S, Cheng X, Yue D, Zhu W, Lin J, et al. Clinical features and long exercise test in Chinese patients with AndersenTawil syndrome. Muscle Nerve. 2016;54:1059-63.

4. Zhang L, Benson DW, Tristani-firouzi M, Ptacek LJ, Tawil R, Schwartz PJ, et al. Electrocardiographic features in AndersenTawil syndrome patients with KCNJ2 mutations characteristic $\mathrm{T}$-U-wave patterns predict the KCNJ2 genotype. Circulation. 2005; 111:2720-6

5. Farrera A, Villanueva M, Vizcaíno A, Medina-Bravo P, Balderrábano-Saucedo $N$, Rives $M$, et al. Ontogeny of the facial phenotypic variability in Mexican patients with 22q11.2 deletion syndrome. Head Face Med. 2019;15:29.

6. Ferry Q, Steinberg J, Webber C, FitzPatrick DR, Ponting CP, Zisserman A, et al. Diagnostically relevant facial gestalt information from ordinary photos. Elife. 2014;3:e02020.

7. Yoon G, Oberoi S, Tristani-Firouzi M, Etheridge SP, Quitania L, Kramer JH, et al. Andersen-Tawil syndrome: prospective cohort analysis and expansion of the phenotype. Am J Med Genet A. 2006;140:312-21.

8. Haruna Y, Kobori A, Makiyama T, Yoshida H, Akao M, Doi T, et al. Genotype-phenotype correlations of $\mathrm{KCNJ} 2$ mutations in Japanese patients with Andersen-Tawil syndrome. Hum Mutat. 2007;28:208.

9. Fournier E, Arzel M, Sternberg D, Vicart S, Laforet P, Eymard B, et al. Electromyography guides toward subgroups of mutations in muscle channelopathies. Ann Neurol. 2004;56:650-61.

10. Kokubun N, Aoki R, Nagashima T, Komagamine T, Kuroda Y, Horie M. Clinical and neurophysiological variability in AndersenTawil syndrome. Muscle Nerve. 2019;60:752-7.

11. Kukla P, Biernacka K, Baranchuk A, Jastrz M, Jagodzi M. Electrocardiogram in Andersen-Tawil syndrome. New electrocardiographic criteria for diagnosis of Type-1 Andersen-Tawil syndrome. Curr Cardiol Rev. 2014;10:222-8.

12. Márquez MF, Totomoch-Serra A, Burgoa JA, Méndez A, GómezFlores JR, Nava S, et al. Abnormal electroencephalogram, epileptic seizures, structural congenital heart disease and aborted sudden cardiac death in Andersen-Tawil syndrome. Int J Cardiol. 2015;180:206-9.

13. Totomoch-Serra A, Brito-Carreón CA, de L Muñoz M, CervantesBarragan D, Márquez MF. Mitochondrial polymorphisms in Andersen-Tawil syndrome. Kardiol Pol. 2020;78:581-3.
14. Hennekam RC. Care for patients with ultra-rare disorders. Eur J Med Genet. 2011;54:220-4

15. Tawil R, Ptacek LJ, Pavlakis SG, Devivo DC, Penn AS, Ozdemir C, et al. Andersen's syndrome : potassium-sensitive periodic paralysis, ventricular ectopy, and dysmorphc features. Ann Neurol. 1994;35:326-30

16. Kimura H, Zhou J, Kawamura M, Itoh H, Mizusawa Y, Ding WG, et al. Phenotype variability in patients carrying KCNJ2 mutations. Circ Cardiovasc Genet. 2012;5:344-53.

17. Plaster NM, Tawil R, Tristani-Firouzi M, Canún S, Bendahhou S, Tsunoda A, et al. Mutations in Kir2.1 cause the developmental and episodic electrical phenotypes of Andersen's syndrome. Cell. 2001;105:511-9.

18. Claes P, Liberton DK, Daniels K, Rosana KM, Quillen EE, Pearson $\mathrm{LN}$, et al. Modeling 3D facial shape from DNA. PLoS Genet. 2014;10:e1004224.

19. Hurst AC. Facial recognition software in clinical dysmorphology. Curr Opin Pediatr. 2018;30:701-6.

20. Bendahhou S, Fournier E, Gallet S, Ménard D, Larroque MM, Barhanin J. Corticosteroid-exacerbated symptoms in an Andersen's syndrome kindred. Hum Mol Genet. 2007;16:900-6.

21. Tan SV, Matthews E, Barber M, Burge JA, Rajakulendran S, Fialho $D$, et al. Refined exercise testing can aid DNA-based diagnosis in muscle channelopathies. Ann Neurol. 2011;69:328-40.

22. de Campos CF, de Carvalho M. Neurophysiologic characterization of periodic paralysis episode in a patient with AndersenTawil syndrome. Clin Neurophysiol. 2018;129:558-9.

23. Tan SV, Z'graggen WJ, Boërio D, Rayan DL, Howard R, Hanna $M G$, et al. Membrane dysfunction in Andersen-Tawil syndrome assessed by velocity recovery cycles. Muscle Nerve. 2012; 46:193-203

24. Ballester LY, Benson DW, Wong B, Law IH, Mathews KD, Vanoye CG, et al. Traffiking-competent and traffiking-defective KCNJ2 mutations in Andersen syndrome. Hum Mutat. 2006;27:388.

25. Rai MK Pai R, Prabhu MA, Pasha SW, Kedambadi RC, Kamath P et al. Short-term response to phenytoin sodium in AndersenTawil syndrome-1 with a cardiac-dominant phenotype. Pacing Clin Electrophysiol. 2019;42:201-7.

26. Lopes CM, Zhang H, Rohacs T, Jin T, Yang J, Logothetis DE. Alterations in conserved Kir channel-PIP2 interactions underlie channelopathies. Neuron. 2002;34:933-44

27. Donaldson MR, Jensen JL, Firouzi MT, Tawil R, Bendahhou S, Suarez WA, et al. PIP2 binding residues of Kir2. 1 are common targets of mutations causing Andersen syndrome. Neurology. 2003;60:1811-6.

28. Lefter S, Hardiman O, Costigan D, Lynch B, McConville J, Hand $\mathrm{CK}$, et al. Andersen-Tawil syndrome with early fixed myopathy. J Clin Neuromuscul Dis. 2014;16:79-82.

29. Davies NP, Imbrici P, Fialho D, Herd C, Bilsland LG, Weber A, et al. Andersen-Tawil syndrome: new potassium channel mutations and possible phenotypic variation. Neurology. 2005; 65:1083-9.

30. Tengan CH, Antunes AC, Baubab JR, Baubab JR. Andersen syndrome: an association of periodic paralysis, cardiac arrhythmia and dysmorphic abnormalities. Arq Neuropsiquiatr. 2006; 64:582-4.

31. Junker J, Haverkamp W, Schulze-Bahr E, Eckardt L, Paulus W, Kiefer R. Amiodarone and acetazolamide for the treatment of genetically confirmed severe Andersen syndrome. Neurology. 2002;59:466.

32. Schoonderwoerd BA, Wiesfeld AC, Wilde AA, van den Heuvel F, Van Tintelen JP, van den Berg MP, et al. A family with AndersenTawil syndrome and dilated cardiomyopathy. Hear Rhythm. 2006;3:1346-50

33. Ardissone A, Sansone V, Colleoni L, Bernasconi P, Moroni I. Intrafamilial phenotypic variability in Andersen-Tawil syndrome: a diagnostic challenge in a potentially treatable condition. Neuromuscul Disord. 2016;27:233-7.

34. Andelfinger G, Tapper AR, Welch RC, Vanoye CG, George AL Jr., Benson DW. KCNJ2 mutation results in Andersen syndrome with sex-specific cardiac and skeletal muscle phenotypes. Am J Hum Genet. 2002;71:663-8.

35. Airey KJ, Etheridge SP, Tawil R, Tristani-Firouzi M. Resuscitated sudden cardiac death in Andersen-Tawil syndrome. Heart Rhythm. 2009;6:1814-7

36. Mazzanti A, Guz D, Trancuccio A, Pagan E, Kukavica D, Chargeishvili T, et al. Natural history and risk stratification in Andersen-Tawil syndrome Type 1. J Am Coll Cardiol. 2020; 75:1772-4 